\title{
Introduction to the Special Issue on GaLA Conf 2020
}

\author{
Iza Marfisi-Schottman ${ }^{l}$, Ludovic Hamon ${ }^{1}$, Roland Klemke ${ }^{2}$, Pierre Laforcade ${ }^{1}$, \\ Francesco Bellotti ${ }^{3}$ \\ ${ }^{1}$ Le Mans Université, EA 4023, LIUM, 72085 Le Mans, France, \\ \{iza.marfisi, ludovic.hamon, pierre.laforcade\}@univ-lemans.fr \\ ${ }^{2}$ Open University of the Netherlands, Heerlen, The Netherlands, \\ roland.klemke@ou.nl \\ ${ }^{3}$ Università degli Studi di Genova, franz@elios.unige.it
}

This special issue of the International Journal of Serious Games offers very valuable extensions to the best papers of the 2020 edition of the GaLA conference. Because of the Covid-19 global pandemic, this edition was organized online, in the Laval Virtual World, a 3D interactive world created by Virbela. The local organization committee was composed of computer scientists of Laval (France), affiliated to Le Mans Université.

From the $9^{\text {th }}$ to the $10^{\text {th }}$ of December 2020, 500 participants attended to a wellorganized conference, through their virtual avatars, and listened to 37 presentations on Serious Games and Gamification. A special session was related to Virtual Reality, in a pedagogical and gaming context.

The four extended papers, published in this journal, significantly extend their original work, and were accepted through a regular peer-review process for this special issue.

"Gamified Learning Theory: The Moderating role of learners' learning tendencies", by Zaric et al. [1], investigates the moderator role of learning tendencies on gamification success concerning learners' academic participation, engagement, and experience. For this, the Felder-Silverman Learning Style Model is used for the identification of learners' tendencies. Sixty-nine Computer Science students were randomly assigned to one control and two treatment groups. Students in the treatment groups were assigned two different gamified courses, while the control group attended a non-gamified course. This allowed the authors to analyze the individual effect of each gamification design and compare and see which gamification design was more appropriate for a learner with particular tendencies. Results indicate that gamification design positively contributes to academic participation, affects learners' engagement in gamified environments, and that students' learning tendencies moderated students' engagement.

"Effects of a videogame in math performance and anxiety in primary school", by Rocha and Dondio [2], describes the design and evaluation of a videogame developed to support math education and overcome math anxiety (MA) at the primary school level. The game narrative is based on the history of math, as the player travels back in time and meets characters such as Pythagoras of Samos and Ada Lovelace, learning about how math was used during their times. The game was evaluated through an experiment that lasted five weeks, involving 88 students from primary schools played the game on weekly sessions 45-60 minutes long. Statistical analysis suggested the game significantly improves students' math performance. Results indicated that female students had higher MA levels in one of the 
pag. 44

classrooms after playing the game. Qualitative data shows students had a high level of engagement with the gameplay.

"Flow Experience and Situational Interest in Game-Based Learning: Cousins or Identical Twins", by Kiili et al. [3], investigated to what extent flow experience and situational interest are different indicators of engagement in game-based learning. Experimental results with Finnish 5th graders revealed that, although flow was not related to learning gains, it seems to be a more competence-oriented construct than situational interest as it was positively correlated with in-game performance. The design of the game successfully supported weaker students with adaptive scaffolds and in-game self-reporting measures worked well. Taken together, even though situational interest and flow share similar components, both constructs are important for multifaceted assessment of engagement in game-based learning.

"Reflections on Ludification: Approaching a Conceptual Framework - and Discussing Inherent Challenges", by Bo Kampmann [4], discusses the concept of ludification with the attempt of laying the theoretical groundwork for further studies. The paper is intended as a prolegomenon to the interpretation of works of ludification, as well as to the field of deploying gamified material in didactical and pedagogical context. The author also proposes an analytical method for unearthing the traits and structures of ludification, called ludointerpretation.

\section{References}

[1] N. Zaric, R. Roepke, V. Lukarov, U. Schroeder, "Gamified Learning Theory: The Moderating role of learners' learning tendencies," International Journal of Serious Games, 8(3), 45-70, 2021. https://doi.org/10.17083/ijsg.v8i3.438

[2] M. Rocha, P. Dondio, "Effects of a videogame in math performance and anxiety in primary school," International Journal of Serious Games, 8(3), 71-91, 2021. https://doi.org/10.17083/ijsg.v8i3.434

[3] K. Kiili, A. Lindstedt, A. Koskinen, H. Halme, M. Nianus, J. McMullen, "Flow Experience and Situational Interest in Game-Based Learning: Cousins or Identical Twins," International Journal of Serious Games, 8(3), $93-114,2021$. https://doi.org/10.17083/ijsg.v8i3.462

[4] B. Kampmann, "Reflections on Ludification: Approaching a Conceptual Frameworkand Discussing In-herent Challenges," International Journal of Serious Games, 8(3), 115-127. 2021, https://doi.org/10.17083/ijsg.v8i3.436 